\title{
A STUDY OF CHANNEL WATER CURRENT VELOCITY METER WITH HORIZONTAL AND VERTICAL AXIS PROPELLER TYPE
}

\author{
Rahmat Permana ${ }^{1}$, Bambang Agus Kironoto ${ }^{2}$, Istiarto ${ }^{2}$ \\ ${ }^{1}$ Staf Pengajar Jurusan Teknik Sipil Politeknik Negeri Bandung Jl. Gegerkalong Hilir Ds.Ciwaruga \\ Bandung 40012. Email: permana.rahmat@ rocketmail.com \\ ${ }^{2}$ Staf pengajar Jurusan Teknik Sipil dan Lingkungan, Fakultas Teknik, Universitas gadjah Mada \\ Bulaksumur, Yogyakarta 55281
}

\begin{abstract}
ABSTRAK
Current meter adalah salah satu alat ukur kecepatan air. Pada umumnya current meter yang ada di pasaran dibuat oleh pabrik-pabrik di luar negeri dan dalam negeri. Pada rancang bangun ini dibuat alat ukur kecepatan air di saluran dengan tipe propeller poros horisontal dan vertikal terbuat dari bahan resin yang diperkuat dengan bahan fiberglass, sensor putaran menggunakan read switch, pencatat putaran (counter) menggunakan panel meter dengan 7 segmen yang menampilkan 4 angka dan dilengkapi dengan pewaktu yaitu berupa timer switch dengan durasi maksimum 5 menit. Berdasarkan hasil yang didapat dengan penerapan berbagai bahan dan modul yang digunakan dalam rancang bangun ini dapat terintegrasi dengan baik. Current meter tipe propeller poros horisontal dapat beroperasi pada kisaran kecepatan $0,040-2,500 \mathrm{~m} / \mathrm{s}$ dan tipe propeller poros vertikal dapat beroperasi pada kisaran kecepatan $0,100-1,250 \mathrm{~m} / \mathrm{s}$.
\end{abstract}

Kata kunci: resin, fiberglass, read switch, panel meter,timer switch

\section{Pendahuluan}

\section{I.1.Latar Belakang}

Untuk mengetahui besarnya debit suatu saluran, salah satu cara yang sering dilakukan adalah dengan cara melakukan pengukuran langsung. Banyak peralatan yang dapat digunakan untuk mengukur debit aliran, yang diantaranya dengan menggunakan current meter. Debit aliran dapat diperoleh melalui pengukuran kecepatan dan luas tampang aliran. Pengukuran debit aliran pada suatu saluran sangat diperlukan untuk mengetahui potensi sumber daya air guna keperluan irigasi, rekayasa dan rekreasi.

Karakteristik saluran yang berbeda-beda menimbulkan permasalahan terhadap usaha pengukuran debit aliran. Hal ini diantaranya disebabkan alat ukur kecepatan aliran (current meter) tidak selalu tepat digunakan untuk tipe saluran tersebut. Current meter yang diproduksi pabrik memiliki keterbatasan kisaran kecepatan minimal yang harus dipenuhi. Selain itu minimnya keterampilan operator juga menjadi hambatan bagi keberhasilan pengukuran.

Salah satu alternatif solusi adalah rancang bangun current meter yang diusahakan sesuai kondisi saluran di Indonesia. Terdapat dua macam current meter yang dirancang, dibuat dan selanjutnya dikaji yaitu tipe poros horisontal dan vertikal. Dua current meter ini diharapkan mampu mengukur kecepatan aliran secara efektif dalam jenis aliran dengan kisaran kecepatan tertentu.

\section{I.2 Tujuan Penelitian}

Penelitian ini bertujuan menghasilkan sebuah prototipe alat ukur kecepatan air (current meter) yang dapat digunakan dalam survey pengukuran. Selanjutnya alat ukur yang dihasilkan dikalibrasi dan diuji validitasnya pada saluran Mataram.

\section{I.3 Batasan Masalah}

Agar penelitian tidak menyimpang dari tujuan pembatasan perlu dilakukan sebagai berikut ini.

1. Current meter yang dibuat direncanakan untuk kedalaman air $150 \mathrm{~cm}$.

2. Daya listrik yang digunakan adalah arus DC 9 Volt.

3. Propeller yang dirancang dan dibuat berbentuk poros horisontal dan vertikal.

4. Panel meter (counter) atau pencatat putaran terdiri dari 7 segmen yang menampilkan 4 angka.

5. Diameter propeller untuk poros horisontal sebesar $12 \mathrm{~cm}$ dan vertikal $10 \mathrm{~cm}$. 


\section{Tinjauan Pustaka}

Rancang bangun alat ukur kecepatan aliran merupakan usaha menciptakan suatu alat yang murah namun tetap memenuhi kaidah keteknikan. Sebuah current meter yang ideal harus memiliki respon yang cepat dan konsisten dengan setiap perubahan yang terjadi pada kecepatan air. Indikator lain kinerja current meter yang lain adalah tingkat ketahan-lamaan dan kemudahan dalam pemeliharaan. Faktor biaya juga sangat penting mengingat current meter produksi pabrik yang dijual di pasar belum sepenuhnya sesuai dengan karakteristik saluran di Indonesia.

Peneliti telah memulai merancang current meter ekonomis yang digunakan untuk mengukur kecepatan aliran di lokasi penelitian. Berikut rancang bangun yang telah dilakukan peneliti sebelumnya:

\section{Rancangan Bangun Current Meter}

Prajitno S (1994) merancang bangun digital current meter untuk mengukur kecepatan aliran air untuk sungai (saluran terbuka). Alat ini terdiri atas sensor kecepatan yang berupa baling-baling (propeller), sensor optic, pengolah data, rangkaian multiplek digit peraga, dan peraga 4 digit. Uji coba alat menunjukkan bahwa digital current meter yang dibuat bekerja untuk kecepatan aliran dari $0,073 \mathrm{~m} / \mathrm{s}$ sampai $18,05 \mathrm{~m} / \mathrm{s}$. Kelebihan alat ini juga menyediakan skala dalam $\mathrm{km} / \mathrm{jam}$ sebagai alternatif waktu pencatatan. Kesalahan maksimum pengukuran kecepatan aliran air alat ini hanya sebesar $17,7 \%$.

\section{Alat Ukur Kecepatan Aliran Air}

Current meter merupakan sebuah alat yang ditenggelamkan ke dalam air bergerak yang dilengkapi dengan rotor (komponen yang berputar) untuk mengetahui kecepatan aliran. Alat ini secara aktual mengukur kecepatan titik pengukuran arus air pada tampang saluran yang terdiri dari:

1. Rotor yaitu bagian yang berputar. Bagian ini diletakkan dimasukkan ke dalam aliran air.

2. Alat kalibrasi yang dapat menunjukkan validitas atau keandalan current meter tersebut.

Alat ini dapat didesain atau dioperasikan:

1. Dengan saklar/switch listrik yang digerakkan oleh baling-baling dan gelombang listrik pendek satu arah yang dapat dideteksi dengan alat khusus atau counter yang tidak berada di dalam air, disambungkan dengan alat ukur arus melalui sebuah kabel listrik,

2. Dengan menggunakan generator arus D.C dengan ketepatan tinggi yang menyediakan voltase/tegangan listrik sesuai dengan kecepatan rotasi baling-baling. Sistem yang paling sering digunakan adalah sistem dengan saklar listrik.

\section{Prinsip-prinsip Pengukuran}

Bagian yang berputar karena aliran air menggerakkan sebuah sistem penunjuk yang memungkinkan jumlah perputaran " $\mathrm{N}$ ", yang dilakukan dalam waktu " $\mathrm{T}$ ”, dapat dihitung atau dicatat.

Kecepatan aliran dihitung dari jumlah putaran baling-baling per detik, dan rumus untuk alat ukur arus

$$
\mathrm{n}=\mathrm{N} / \mathrm{T} \text {. }
$$

Rumus ini merupakan hubungan antara kecepatan aliran air dimana alat ukur arus ditenggelamkan dengan parameter-parameter yang terdeteksi, yaitu jumlah putaran balingbaling " $\mathrm{N}$ ", pada waktu tertentu " $\mathrm{T}$ ".

Persamaan yang menghubungkan kecepatan air, v, dengan kecepatan putaran baling-baling secara teori adalah linear, dalam bentuk $\mathrm{v}=\mathrm{kn}$ $(\mathrm{k}=$ pitch propeller $)$ tanpa terjadi gesekan .

Akan tetapi, karena terjadi gesekan mekanis dan kehilangan hidraulik, persamaan merupakan garis lengkung yang hampir-hampir menggambarkan garis lurus. Pengalaman menunjukkan bahwa garis lengkung dapat diperkirakan dengan satu atau lebih garis lurus, sehingga rumus kalibrasi secara efektif linear pada kisaran kecepatan tertentu dan dapat dinyatakan oleh satu atau lebih garis lurus yang ditulis dalam bentuk persamaan: $\mathrm{v}=\mathrm{an}+\mathrm{b}$

dimana:

$\mathrm{v}=$ kecepatan aliran $(\mathrm{m} / \mathrm{s})$

$\mathrm{n}=$ jumlah putaran propeller per detik

$\mathrm{a}=$ pitch propeller $(\mathrm{m})$

$\mathrm{b}=$ kecepatan "start/awal"

Koefisien-koefisien a dan b ditentukan melalui percobaan selama melakukan kalibrasi alat ukur (current meter). 


\section{Metode Penelitian}

Proses rancang bangun dilakukan di Workshop Bandung, sebagai tempat pengujian per bagian dari rangkaian sistem sampai pekerjaan kalibrasi.

\section{Rancangan Current Meter}

Desain rancang bangun alat ukur kecepatan aliran air (current meter) secara keseluruhan meliputi tiga bagian utama. Propeller merupakan bagian paling ujung dari desain alat yang berfungsi sebagai pendeteksi besarnya kecepatan aliran air. Komponen kedua berupa sensor yang berguna mendeteksi kecepatan putaran yang dihasilkan oleh propeller. Bagian selanjutnya berupa perekam putaran (counter), untuk menunjukkan secara visual banyaknya digit/angka putaran yang dihubungkan oleh suatu kabel ke bagian sensor. Seperti ditampilkan pada Gambar 1.

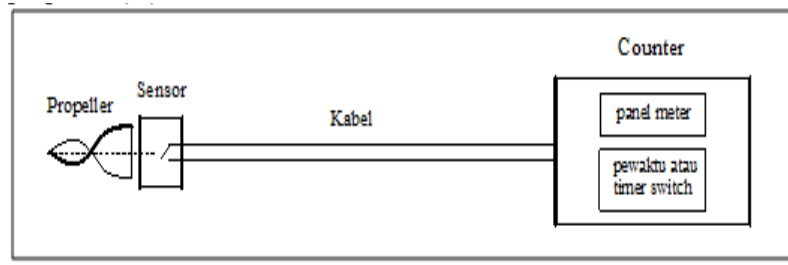

Gambar 1. Desain rancang bangun currnet meter

Perancangan Pengabelan (wiring)

Pengabelan merupakan penghubung dari bagian-bagian komponen elektronik seperti sensor propeller, modul timer switch, panel meter/counter, battery, saklar-saklar dan sebagainya menjadi suatu rangkaian elektronik yang bersinergi sesuai dengan fungsi yang direncanakan, dapat dilihat pada Gambar 2.

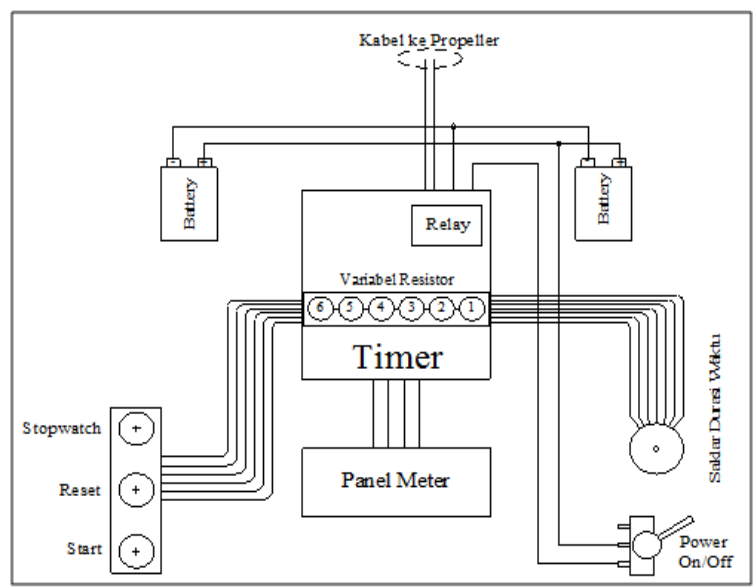

Gambar 2. Diagram block pada counter/ wirring counter

\section{IV.Hasil dan Pembahasan}

Pengujian Hasil Rancangan

Current meter yang dirancang dan dibuat membutuhkan pengujian. Pengujian dilakukan agar unjuk kerja alat dapat diketahui. Jenis pengujian yang dilakukan sebagai berikut ini.

1. Kalibrasi alat current meter.

Pengujian kalibrasi bertujuan untuk menyesuaikan keluaran pengukuran terhadap besaran standar yang berlaku yang dilakukan setelah masing-masing komponen alat dirakit.

2. Pengujian pengukuran kecepatan di lapangan.

Pengujian pengukuran kecepatan bertujuan untuk melihat unjuk kerja alat current meter pada saluran nyata/lapangan (Saluran Mataram) dengan cara membandingkan hasil pengukuran kedua macam propeller satu terhadap lainnya.

\section{Kalibrasi}

Alat kalibrasi yang digunakan berupa saluran kalibrasi yang dilengkapi dengan kereta kalibrasi. Pengukuran kecepatan kereta (v) yang bergerak menunjukkan kecepatan relatif antara air dan current meter, dan pengukuran kecepatan putaran propeller pun dapat menyimpulkan persamaan untuk alat current meter dalam bentuk $\mathrm{n}=\mathrm{N} / \mathrm{T}$. Kalibrasi current meter membutuhkan beberapa data hubungan antara kecepatan air dengan kecepatan putaran propeller dimana alat ukur ditenggelamkan. Adapun data yang diambil selama melakukan kalibrasi merupakan waktu tempuh (T) untuk mencapai banyaknya putaran tertentu $(\mathrm{N})$, dengan kecepatan kereta yang tertentu pula (v).

Uji Pengukuran Lapangan

Uji pengukuran lapangan merupakan langkah terakhir kajian rancang bangun current meter. Masing-masing propeller mengukur lima kali secara bergantian dengan durasi waktu yang bervariasi 30; 40; 50; 60; 90; 120; 180; 240 dan 300 detik pada satu titik pengukuran di tengah saluran pada kedalaman $60 \%$ di Saluran Mataram. Kedalaman air di tengah-tengah saluran $65 \mathrm{~cm}$. Uji ini bertujuan untuk melihat unjuk kerja masing-masing current meter terutama berkaitan dengan sesitifitas dan kestabilan pembacaan kecepatan. Dalam tahap ini juga dilakukan pembandingan hasil pengukuran dua macam propeller yang dibuat. 
Hasil Kalibrasi Current Meter Poros Horisontal

Data kalibrasi poros horisontal dan vertikal disajikan secara berturut-turut dapat dilihat pada Tabel 1 dan 2.

Tabel 1. Data kalibrasi propeller poros horisontal

\begin{tabular}{|c|c|c|c|c|c|c|}
\hline No & \begin{tabular}{|c|} 
Kecepatan \\
kereta \\
$(\mathrm{m} / \mathrm{s})$
\end{tabular} & $\begin{array}{c}\text { Putaran } \\
\text { (N) }\end{array}$ & $\begin{array}{l}\text { Waktu (T) } \\
\text { N putaran } \\
\text { (detik) }\end{array}$ & $\begin{array}{c}\text { Kecepatan } \\
\text { putaran } \\
(\mathrm{n}=\mathrm{N} / \mathrm{T})\end{array}$ & $\begin{array}{c}\text { Kecepatan rerata } \\
\text { kereta pada jarak } \\
10 \mathrm{~m}(\mathrm{~m} / \mathrm{s})\end{array}$ & $\begin{array}{c}\text { Waktu } \\
\text { tempuh } 10 \mathrm{~m} \\
\text { (detik) }\end{array}$ \\
\hline 1 & 700640 & 10 & 88,114 & 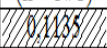 & & \\
\hline 2 & 16 & 10 & 50,320 & 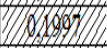 & & \\
\hline 3 & 106 & 10 & 35,488 & 10 & & \\
\hline 4 & DIX & 10 & 27,250 & 20 & & \\
\hline 5 & 0,200 & 20 & 25,660 & 0,7794 & & \\
\hline 6 & 0,300 & 20 & 16,775 & 1,1923 & & \\
\hline 7 & 0,400 & 20 & 12,472 & 1,6046 & & \\
\hline 8 & 0,500 & 20 & 9,899 & 2,0204 & & \\
\hline 9 & 1,001 & 30 & 7,350 & 4,0825 & 1,001 & 9,991 \\
\hline 10 & 1,501 & 30 & 4,873 & 6,1564 & 1,501 & 6,663 \\
\hline 11 & 2,002 & 30 & 3,652 & 8,2157 & 2,002 & 4,995 \\
\hline 12 & 2,502 & 30 & 2,923 & 10,2634 & 2,502 & 3,997 \\
\hline
\end{tabular}

Pada tabel 1 terlihat kecepatan kereta dimulai pada kecepatan $0,040 \mathrm{~m} / \mathrm{s}$. Hal ini dikarenakan saat melakukan kalibrasi pada kecepatan kurang dari $0,040 \mathrm{~m} / \mathrm{s}$, propeller poros horisontal belum merespon (belum berputar). Fakta ini menunjukkan bahwa batas minimal kemampuan propeller mengukur arus adalah pada kecepatan $0,040 \mathrm{~m} / \mathrm{s}$.

Persamaan kecepatan current meter untuk $\mathrm{n} \leq$ 0,47 didapat dengan cara meregresi hubungan kecepatan putaran dengan kecepatan kereta yang dimulai dari nomor 1 sampai nomor 4 , seperti yang ditampilkan pada Tabel 1 bagian yang diarsir dan untuk $n>0,47$ didapat dengan cara meregresi mulai dari nomor 5 sampai nomor 12 pada Tabel 1 bagian yang tidak diarsir. Hasil regresi masing-masing dapat dilihat pada Gambar 3 dan 4.

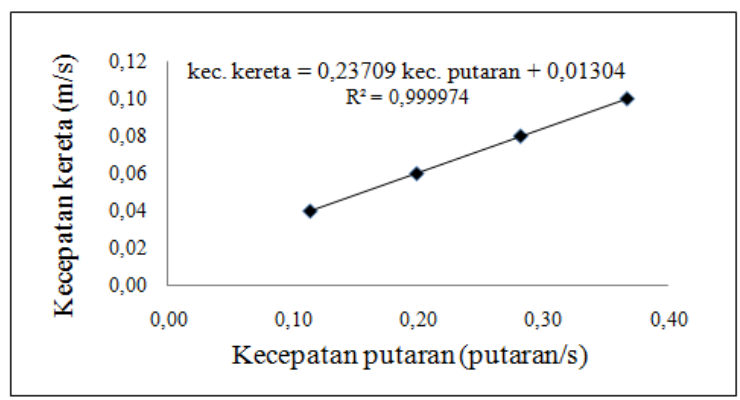

Gambar 3. Kurva regresi hubungan kecepatan putaran dengan kecepatan kereta propeller poros horisontal untuk $\mathrm{n} \leq$ 0,47 .

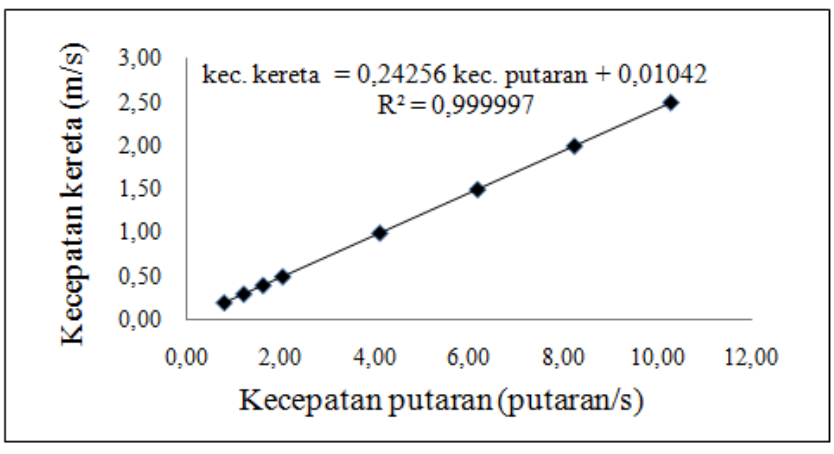

Gambar 4. Kurva regresi hubungan kecepatan putaran dengan kecepatan kereta propeller poros horisontal untuk $\mathrm{n}$ $>0,47$.

\section{Hasil Kalibrasi Current Meter Poros Vertikal}

Rumus persamaan kecepatan current meter poros vertikal didapat dengan cara meregresi hubungan kecepatan putaran dengan kecepatan kereta mulai dari nomor 1 sampai nomor 11 pada Tabel 2. Hasil regresinya ditampilkan pada Gambar 5. Pada Tabel 2 terlihat bahwa kecepatan kereta dimulai pada kecepatan 0,100 $\mathrm{m} / \mathrm{s}$.

Hal ini dikarenakan saat melakukan kalibrasi pada kecepatan kurang dari $0,100 \mathrm{~m} / \mathrm{s}$, propeller poros vertikal belum merespon (belum berputar). Fakta ini menunjukkan bahwa batas minimal kemampuan propeller vertikal dalam mengukur arus adalah pada kecepatan $0,100 \mathrm{~m} / \mathrm{s}$.

Tabel 2. Data kalibrasi propeller poros vertikal

\begin{tabular}{|c|c|c|c|c|c|c|}
\hline No & $\begin{array}{c}\text { Kecepatan } \\
\text { kereta } \\
(\mathrm{m} / \mathrm{s})\end{array}$ & $\begin{array}{c}\text { Putaran } \\
(\mathrm{N})\end{array}$ & $\begin{array}{c}\text { Waktu (T) } \\
\text { N putaran } \\
(\text { detik })\end{array}$ & $\begin{array}{c}\text { Kecepatan } \\
\text { putaran } \\
(\mathrm{n}=\mathrm{N} / \mathrm{T})\end{array}$ & $\begin{array}{c}\text { Kecepatan rerata } \\
\text { kereta pada jarak } \\
10 \mathrm{~m}(\mathrm{~m} / \mathrm{s})\end{array}$ & $\begin{array}{c}\text { Waktu } \\
\text { tempuh } 10 \mathrm{~m} \\
(\text { detik })\end{array}$ \\
\hline 1 & 0,100 & 10 & 64,103 & 0,1560 & & \\
\hline 2 & 0,200 & 10 & 28,807 & 0,3471 & & \\
\hline 3 & 0,300 & 10 & 18,706 & 0,5346 & & \\
\hline 4 & 0,400 & 20 & 27,497 & 0,7274 & & \\
\hline 5 & 0,500 & 20 & 21,694 & 0,9219 & & \\
\hline 6 & 0,600 & 20 & 18,050 & 1,1080 & & \\
\hline 7 & 0,700 & 20 & 15,411 & 1,2978 & & 9,979 \\
\hline 8 & 0,800 & 30 & 20,140 & 1,4896 & & 7,993 \\
\hline 9 & 0,900 & 30 & 17,856 & 1,6801 & & \\
\hline 10 & 1,002 & 30 & 16,004 & 1,8745 & 1,002 & \\
\hline 11 & 1,251 & 30 & 12,772 & 2,3489 & 1,251 & \\
\hline
\end{tabular}




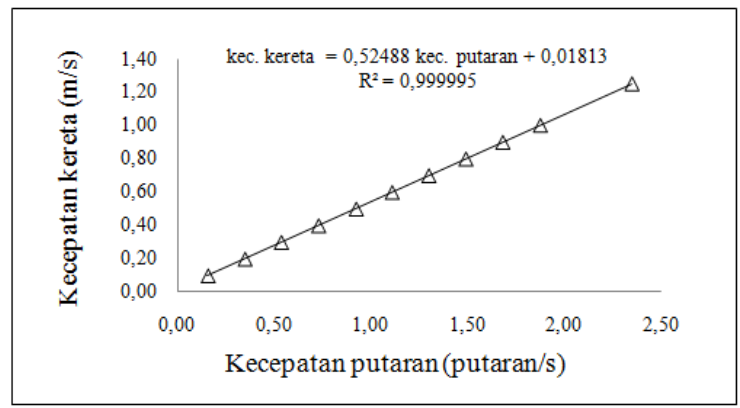

Gambar 5. Kurva regresi hubungan kecepatan putaran dengan kecepatan kereta poros vertikal

\section{Hasil Uji Pengukuran Lapangan}

Hasil pengujian lapangan kedua alat current meter disajikan dalam bentuk Gambar 6 berikut ini.

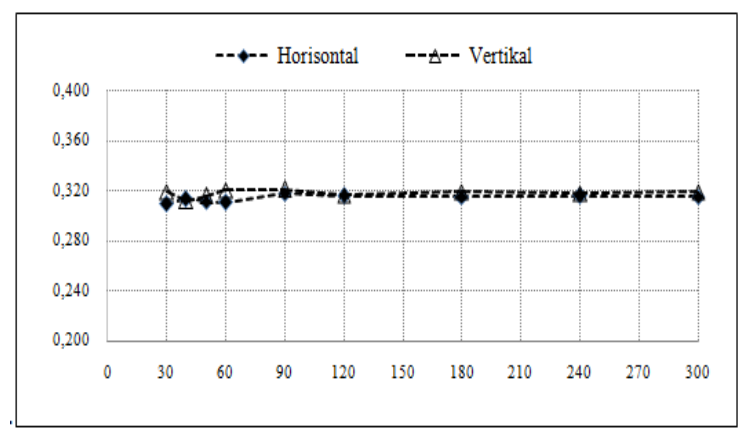

Gambar 6. Kecepatan air rerata untuk berbagai durasi waktu pengukuran poros horizontal dan vertikal

Gambar 6 memberikan pemahaman bahwa hasil pengujian lapangan kedua alat current meter menunjukan bahwa current. meter poros horisontal memberikan kestabilan yang lebih baik dibandingkan dengan poros vertikal.

\section{V.Kesimpulan dan Saran}

\section{V.1 Kesimpulan}

Telah dibuat alat ukur kecepatan air di sungai (current meter) tipe propeller poros horisontal dan vertikal dengan karaktristik sebagai berikut ini.

1. Rumus persamaan kecepatan tipe propeller poros horisontal. $\mathrm{v}=0,2371 \mathrm{n}+0,0130$ ini berlaku jika nilai $\mathrm{n} \leq 0,47$ dan $\mathrm{v}=0,2426 \mathrm{n}+0,0104$ ini berlaku jika nilai $\mathrm{n}>0,47$ dengan batas kisaran kecepatan antara $0,040-2,500 \mathrm{~m} / \mathrm{s}$.
2. Rumus persamaan kecepatan tipe propeller poros vertikal. $\mathrm{v}=0,5249 \mathrm{n}+0,0181$ dengan batas kisaran kecepatan $0,100-1,250 \mathrm{~m} / \mathrm{s}$.

3. Alat ukur kecepatan air (current meter) tipe propeller poros horisontal lebih stabil dibandingkan dengan tipe propeller poros vertikal dengan durasi $\mathrm{T} 90$ detik sampai 300 detik.

\section{V.2 Saran}

1. Berkaitan dengan sensitifitas pada kecepatan rendah dapat diperbaiki (dibuat lebih sensitif) dengan mengembangkan pada poros propeller agar hambatan geseknya lebih kecil. Ini mungkin bisa ditempuh dengan cara pada bantalan poros propeller menggunakan bearing dengan syarat pembuatan nya lebih presisi dengan memanfaatkan mesin bor/bubut computer numerical control (CNC). Sedangkan pada rancang bangun ini menggunakan peralatan tangan dan pemborannya dilakukan dengan sekala mata.

2. Perlu dikembangkan current meter tipe propeller poros horisontal dengan beberapa variasi diameter, kemiringan blade/pitch propeller, banyaknya blade untuk melihat unjuk kerja/karakteristik propeller tersebut sehingga kisaran kecepatan yang dapat diukur menjadi lebih lebar.

3. Untuk pengembangan lebih lanjut mengenai rancang bangun current meter perlu adanya kajian tentang hidrodinamika air supaya supaya hasil rancangannya lebih sempurna.

\section{Daftar Pustaka}

Ahmad, J., (2007): Elektronik Dasar www.salonnet.info/ebooks-pdf-docelektronika+dasar+html.15.30

Istiarto, (2009): Hand Out Hidrometri Sungai, Program Studi Teknik Sipil Pascasarjana Universitas Gajah Mada, Yogyakarta.

Istiarto, (2003): Dikat Kuliah Statistik, Program Studi Teknik Sipil Pascasarjana Universitas Gadjah Mada, Yogyakarta. 
Kironoto. B.A.,(2004): Diktat Kuliah Model Hidrolika, Program Studi Teknik Sipil Pascasarjana Universitas Gajah Mada, Yogyakarta.

Kironoto.B.A.,(2004): Hand Out Hidrolika, Program Studi Teknik Sipil Pascasarjana Universitas Gajah Mada, Yogyakarta.

Prajitno, S., (1994): Digital Current Meter, Alat Pengukur Aliran Air Untuk Sungai, ISSN 0852-002 X, PPI-KIM 1994, Tangerang.

Rochmadi, (2010):, Teknologi Polimer, Jurusan Teknik Kimia Fakultas Teknik Universitas Gajah Mada.

Sri Harto, BR., (2000):, Hidrologi, ISBN 979861- 24 -1, Nafiri Offset, Yogyakarta.

Skeeter, V.L and Wylie, E.B, (1991): Mekanika Fluida, Edisi Delapan Jilid 1, Erlangga, Jakarta.

Skeeter, V.L and Wylie, E.B, (1991): Mekanika Fluida, Edisi Delapan Jilid 2, Erlangga, Jakarta.

Srivastava, A.C., (2006): Teknik Instrumentasi, Universitas Indonesia, Jakarta.

Triatmodjo, B., (2009): Hidrologi Terapan. Beta Offset. Yogyakarta. 